\title{
Influence of Cranberry Proanthocyanidins on Formation of Biofilms by Streptococcus mutans on Saliva-Coated Apatitic Surface and on Dental Caries Development in vivo
}

\author{
H. Koo ${ }^{a-c}$ S. Duarte ${ }^{a}$ R.M. Murata ${ }^{a} \quad$ K. Scott-Anne ${ }^{b} \quad$ S. Gregoire ${ }^{b}$ \\ G.E. Watson ${ }^{a}$ A.P. Singh ${ }^{d}$ N. Vorsa ${ }^{d, e}$ \\ ${ }^{a}$ Eastman Department of Dentistry, ${ }^{b}$ Center for Oral Biology, and ${ }^{c}$ Department of Microbiology and Immunology, \\ University of Rochester Medical Center, Rochester, N.Y., d Department of Plant Biology and Plant Pathology, \\ Rutgers University, New Brunswick, N.J., and ePhilip E. Marucci Center for Blueberry and Cranberry Research and \\ Extension, Rutgers University, Chatsworth, N.J., USA
}

\section{Key Words}

Biofilm · Cranberry · Dental caries · Extracellular matrix ·

Glucans $\cdot$ Glucosyltransferases $\cdot$ Proanthocyanidins

\begin{abstract}
Cranberry crude extracts, in various vehicles, have shown inhibitory effects on the formation of oral biofilms in vitro. The presence of proanthocyanidins (PAC) in cranberry extracts has been linked to biological activities against specific virulence attributes of Streptococcus mutans, e.g. the inhibition of glucosyltransferase (Gtf) activity. The aim of the present study was to determine the influence of a highly purified and chemically defined cranberry PAC fraction on S. mutans biofilm formation on saliva-coated hydroxyapatite surface, and on dental caries development in Sprague-Dawley rats. In addition, we examined the ability of specific PAC (ranging from low-molecular-weight monomers and dimers to highmolecular-weight oligomers/polymers) to inhibit GtfB activity and glycolytic $\mathrm{pH}$ drop by $\mathrm{S}$. mutans cells, in an attempt to identify specific bioactive compounds. Topical applications (60-second exposure, twice daily) with PAC $(1.5 \mathrm{mg} / \mathrm{ml})$ during biofilm formation resulted in less biomass and fewer insoluble polysaccharides than the biofilms treated with ve-
\end{abstract}

hicle control had ( $10 \%$ ethanol, $v / v ; p<0.05$ ). The incidence of smooth-surface caries in rats was significantly reduced by PAC treatment (twice daily), and resulted in less severe carious lesions compared to the vehicle control group $(p<0.05)$; the animals treated with PAC also showed significantly less caries severity on sulcal surfaces $(p<0.05)$. Furthermore, specific A-type PAC oligomers (dimers to dodecamers; 0.1 $\mathrm{mg} / \mathrm{ml}$ ) effectively diminished the synthesis of insoluble glucans by GtfB adsorbed on a saliva-coated hydroxyapatite surface, and also affected bacterial glycolysis. Our data show that cranberry PAC reduced the formation of biofilms by S. mutans in vitro and dental caries development in vivo, which may be attributed to the presence of specific bioactive A-type dimers and oligomers.

Copyright $\odot 2010$ S. Karger AG, Basel

Oral diseases induced by dental plaque continue to afflict the majority of the world's population. Among them, dental caries is the single most prevalent and costly oral infectious disease [Marsh, 2003]. This ubiquitous disease results from the interaction of specific bacteria and constituents of the diet within plaque (a natural biofilm) formed on tooth surfaces. Streptococcus mutans is a key

\section{KARGER}

(C) 2010 S. Karger AG, Basel

Fax +41613061234 E-Mail karger@karger.ch www.karger.com www.karger.com/cre
Hyun Koo

University of Rochester Medical Center

Center for Oral Biology, 601 Elmwood Avenue

Box 611, Rochester, NY 14620 (USA)

Tel. +1 585273 4216, Fax +1 585276 0190,E-Mail hyun_koo@urmc.rochester.edu 
contributor to the formation of cariogenic plaque because this bacterium (i) effectively utilizes dietary sucrose to synthesize large amounts of extracellular polysaccharides (EPS), (ii) adheres tenaciously to glucan-coated surfaces, and (iii) is also highly acidogenic and acid tolerant [Hamada and Slade, 1980; Gibbons, 1984; Bowen, 2002].

The majority of biofilm matrices are rich in polysaccharides, and dental plaque is no exception [Guggenheim, 1970; Hotz et al., 1972; Emilson et al., 1984; Bowen, 2002]. These polysaccharides, mostly glucans synthesized by microbial glucosyltransferases (Gtf), are complex in structure, which change over time during the extracellular matrix development [Kopec et al., 1997; Hayacibara et al., 2004; Reese and Guggenheim, 2007; Xiao and Koo, 2009]. The Gtf secreted by S. mutans (particularly GtfB and GtfC) bind avidly to the pellicle formed on the tooth surface and to surfaces of other oral microorganisms, and are highly active in the adsorbed state [Rölla et al., 1983; Schilling and Bowen, 1988; Vacca Smith and Bowen, 1998]. The glucans synthesized by surfaceadsorbed $\mathrm{GtfB}$ and $\mathrm{GtfC}$ provide specific binding sites for bacterial colonization on the tooth surface and to each other [Schilling and Bowen, 1992], thus contributing to the initial steps of cariogenic plaque development in vivo [Tanzer et al., 1985; Yamashita et al., 1993]. If dental plaque is allowed to remain on tooth surfaces and is exposed to dietary carbohydrates frequently (especially sucrose), S. mutans as a member of the plaque community will continue to synthesize polysaccharides and metabolize the sugars to organic acids. The elevated amount of EPS increases the biofilm stability and structural integrity, and provides protection to the bacteria from inimical influences of antimicrobials and other environmental assaults [Paes Leme et al., 2006; Flemming et al., 2007]. In addition, the ability of $S$. mutans to utilize some extraand intracellular polysaccharides as short-term storage compounds offers an additional ecological benefit simultaneously increasing the amount of acid production and the extent of acidification. The persistence of this acidic environment leads to the selection of a highly acid-tolerant flora [Quivey et al., 2000; Marsh, 2003; Marquis et al., 2003]; the low $\mathrm{pH}$ environment within the plaque's matrix results in the dissolution of enamel, thus initiating the dental caries process. Therefore, EPS and acidification of the biofilm's matrix are critical for the formation and establishment of cariogenic dental plaque [Bowen, 2002; Marsh, 2003], and offer primary targets for chemotherapeutic intervention. The development of novel chemotherapeutic approaches, other than the use of microbiocides, that disrupt the establishment and virulence of biofilms is a promising route to prevent or reduce infectious diseases such as dental caries [Cegelski et al., 2008; Koo, 2008].

Cranberry fruit (Vaccinium macrocarpon Ait., Ericaceae) is a uniquely rich source of various classes of bioactive flavonoids including the flavonols, anthocyanins and proanthocyanidins (PAC), offering a significant therapeutic potential for biofilm-related diseases [Cunningham et al., 2004]. Cranberry juice and hydroalcoholic crude extracts also prevent bacterial adherence to apatitic surfaces and reduce the formation of biofilms by oral bacteria in vitro [Weiss et al., 2002; Steinberg et al., 2002; Yamanaka et al., 2004; Koo et al., 2006; Duarte et al., 2006]. Recently, we have shown that topical applications of PAC-enriched extract significantly reduced the formation, insoluble polysaccharide content and acidogenicity of $S$. mutans biofilms in vitro without displaying bactericidal effects [Duarte et al., 2006; Gregoire et al., 2007]. The biological actions were attributed to the combined inhibitory effects of PAC on the activity of surfaceadsorbed $\mathrm{GtfB}$ and $\mathrm{GtfC}$, and on bacterial glycolysis [Duarte et al., 2006; Gregoire et al., 2007]. However, their potential usefulness to prevent or reduce oral diseases has not been evaluated in vivo, and little is known about the putative PAC bioactivity against $S$. mutans [Gregoire et al., 2007] or other oral pathogens [La et al., 2009].

Therefore, the aims of this study were (1) to examine the influence of a highly purified and chemically defined PAC fraction on the development of dental caries in vivo using a well-established rodent model [Bowen et al., 1988], and (2) to determine the inhibitory effects of specific PAC (ranging from low-molecular-weight monomers and dimers to high-molecular-weight oligomers/ polymers) on glucan synthesis and glycolytic $\mathrm{pH}$ drop by $S$. mutans cells in an attempt to identify the bioactive cranberry compounds.

\section{Materials and Methods}

Cranberry PAC

PAC were extracted from fruit of the cranberry variety 'Stevens' harvested at Rutgers University, P.E. Marucci Center, during September/October 2006 and kept frozen at $-20^{\circ} \mathrm{C}$; the 'Stevens' variety is the main cultivar used in the production of commercially available cranberry products [Cunningham et al., 2004; Duarte et al., 2006]. Cranberry is an appealing source of PAC because it (1) harbors unique A-type PAC in higher concentrations than in other natural food products, (2) is a readily available and commonly consumed fruit, and (3) can be selectively bred to produce elevated levels of biologically active PAC. The PAC were isolated from cranberry hydroethanolic extracts, using aqueous ac- 
etone extraction followed by an ethyl acetate extraction and $\mathrm{LH}$ 20 column chromatography, and dried using a rotavapor as detailed elsewhere [Wilson et al., 2008; Singh et al., 2008]. The PAC composition was characterized using high-performance liquid chromatography (HPLC)-photodiode/electrochemical detection and matrix-assisted laser desorption/ionization (MALDI) time-of-flight (TOF) mass spectrometry (MS) [Wilson et al., 2008; Singh et al., 2008], and further confirmed using LC-MS-MS in product ion scan mode followed by a multiple reaction monitoring (MRM) scan. The identification of high-molecular oligomeric PAC were performed on an API-3000 tandem mass spectrometer (Applied Biosystems, Foster City, Calif., USA) using an electrospray ionization source in negative-ion mode and the following conditions: curtain gas $=10$ psi, nebulizer gas $=9$ psi, collisionally activated dissociation gas $=6 \mathrm{psi}$, TurboIonSpray (ion spray) voltage $=-4,200 \mathrm{~V}$, entrance potential $=-10 \mathrm{~V}$, collision cell exit potential $=-8 \mathrm{~V}$, source temperature $=400^{\circ} \mathrm{C}$, declustering potential $=-60 \mathrm{~V}$. Analytical data were acquired by the Analyst software, version 1.4.2. The product ion spectra for oligomeric PAC and total ion chromatogram in MRM mode are shown in figure 1 .

\section{Bacterial Strains}

S. mutans UA159, a virulent cariogenic pathogen and the strain selected for genomic sequencing [Ajdić et al., 2002], was used for biofilm and animal studies. S. anginosus KSB8 construct (kindly provided by Howard K. Kuramitsu, State University of New York, Buffalo, N.Y., USA), which harbors the gtfB gene from S. mutans GS-5, was used for the production of GtfB (responsible for the synthesis of glucans rich in $\alpha 1,3$-linked glucose). The cultures were stored at $-80^{\circ} \mathrm{C}$ in tryptic soy broth containing $20 \%$ glycerol.

\section{Biofilm Preparation}

Hydroxyapatite disks (surface area of $2.7 \pm 0.2 \mathrm{~cm}^{2}$; Clarkson Chromatography Products Inc., South Williamsport, Pa., USA) were coated with filter-sterilized $(0.22 \mu \mathrm{m}$; polyether sulfone lowprotein-binding filter; Millipore Co., Bedford, Mass., USA) clarified human whole saliva for $1 \mathrm{~h}$ at $37^{\circ} \mathrm{C}$; whole saliva was collected on ice from 1 donor who chewed paraffin film, and it was clarified by centrifugation $\left(8,500 \mathrm{~g}, 4^{\circ} \mathrm{C}, 10 \mathrm{~min}\right.$ ) [Koo et al., 2000]. Biofilms of $S$. mutans UA159 (ATCC 700610) were formed on saliva-coated hydroxyapatite (sHA) disks placed in a vertical position using a disk holder in ultrafiltered (Amicon 10-kDa molecular weight cutoff membrane; Millipore Co.) tryptone-yeast extract broth by addition of $30 \mathrm{~mm}$ sucrose at $37^{\circ} \mathrm{C}$ and $5 \% \mathrm{CO}_{2}$ for 5 days [Koo et al., 2005]. During the first $24 \mathrm{~h}$, the organisms were grown undisturbed to allow initial biofilm formation; the biofilms ( $24 \mathrm{~h}$ old) were then treated twice daily (at $10 \mathrm{a} . \mathrm{m}$. and 4 p.m.) until the 5 th day of the experimental period (120-hour-old biofilms) with one of the following: (1) PAC (1.5 mg of PAC dry weight $/ \mathrm{ml}$ ); (2) $250 \mathrm{ppm}$ of $\mathrm{F}$ (as sodium fluoride; positive control), or (3) vehicle control (10\% ethanol, v/v; negative control). The presence of $10 \%$ ethanol did not affect the ionization of fluoride as determined experimentally. In addition, treatments with $10 \%$ ethanol (1-min exposure, twice daily) allowed the continued formation of biofilm, and did not affect the biochemical composition and cell viability when compared to biofilms treated with saline solution. The biofilms were exposed to the treatments for $1 \mathrm{~min}$, dip-rinsed 3 times in sterile saline solution (to remove ex- cess agents or vehicle control) and transferred to fresh culture medium. The treatments and rinsing procedures were repeated $6 \mathrm{~h}$ later. Each biofilm was exposed to the respective treatment a total of 8 times. Biofilm assays were performed in quadruplicate in at least 3 different experiments.

\section{Biofilm Analyses}

At the end of the experimental period (120-hour-old biofilms), the biofilms were removed and subjected to sonication using three 30 -second pulses at an output of 7 W (Branson Sonifier 150; Branson Ultrasonics, Danbury, Conn., USA) [Koo et al., 2003]. The homogenized suspension was analyzed for biomass (dry weight), total protein (by acid digestion followed by ninhydrin assay) [Moore and Stein, 1954] and polysaccharide composition. The extracellular water-soluble and -insoluble polysaccharides, and intracellular iodophilic polysaccharides were extracted and quantified by colorimetric assays as detailed by Koo et al. [2003] and Duarte et al. [2008]. Briefly, an aliquot $(4 \mathrm{ml})$ of the biofilm suspension was centrifuged at $10,000 \mathrm{~g}$ for $10 \mathrm{~min}$ at $4^{\circ} \mathrm{C}$. The supernatant was collected and the biofilm pellet resuspended and washed in the same volume of water; this procedure was repeated twice. All the supernatants were pooled and 3 volumes of cold ethanol added, and the resulting precipitate (or water-soluble polysaccharides) collected and washed with cold ethanol; the total amount of carbohydrate was determined by the phenol-sulfuric method [Dubois et al., 1956]. The biofilm pellet was dried in a Speed Vac concentrator and used for the determination of (i) extracellular insoluble polysaccharides and (ii) intracellular iodophilic polysaccharides. The insoluble polysaccharides were extracted using $1 \mathrm{~N} \mathrm{NaOH} \mathrm{(1} \mathrm{mg} \mathrm{of} \mathrm{biofilm} \mathrm{dry} \mathrm{weight/} 0.3 \mathrm{ml}$ of $1 \mathrm{~N}$ $\mathrm{NaOH}$ ) under agitation for $2 \mathrm{~h}$ at $37^{\circ} \mathrm{C}$ and quantified by the phenol-sulfuric method. The intracellular iodophilic polysaccharides were extracted with hot $5.3 \mathrm{M} \mathrm{KOH}(0.8 \mathrm{mg}$ of biofilm dry weight $/ \mathrm{ml}$ of $\mathrm{KOH}$ ) and quantified using $0.2 \% \mathrm{I}_{2} / 2 \% \mathrm{KI}$ solution and glycogen as a standard, as described by DiPersio et al. [1974]. Furthermore, the $\mathrm{pH}$ of the culture medium was measured daily at specific time points $(60,120$ and $240 \mathrm{~min}$ after medium replacement) by a glass electrode (Futura Micro Combination $\mathrm{pH}$ electrode; 5 mm diameter; Beckman Coulter Inc., Calif., USA).

\section{Isolation of PAC Dimers and Oligomer Classes}

The cranberry PAC were isolated using directly coupled HPLC-MS and MALDI-TOF-MS systems [Wilson et al., 2008; Singh et al., 2008]. Briefly, PAC containing fractions obtained from methanol and $80 \%$ acetone elution were reloaded on a Sephadex LH-20 column (glass column; size: $100 \times 45 \mathrm{~mm}$ ) and eluted with increased gradients of a methanol and water $(10,20$, $30,40,60$ and $80 \%$ methanol/water) mixture. The PAC obtained from the $80 \%$ acetone/water elution was again chromatographed using a Sephadex LH-20 column. The greater portion of dimers and oligomeric PAC (less than hexamers) were selectively eluted using a mixture of methanol and water (80\% methanol/water) while highly polymerized PACs (DP-6 to DP-12) remained in the column and were successively eluted with $90 \%$ methanol/water, $100 \%$ methanol and, finally, with $60 / 80 \%$ acetone/water to obtain polymeric PAC of molecular weight with a degree of polymerization (DP) ranging from DP-6 to DP-12 and a DP of $>12$ (pentadecamers). The fractions were further separated based on the DP using an MCI gel (CHP 20P) highly porous polymer column. The MCI gel column was successively eluted with $10-50 \%$ metha- 

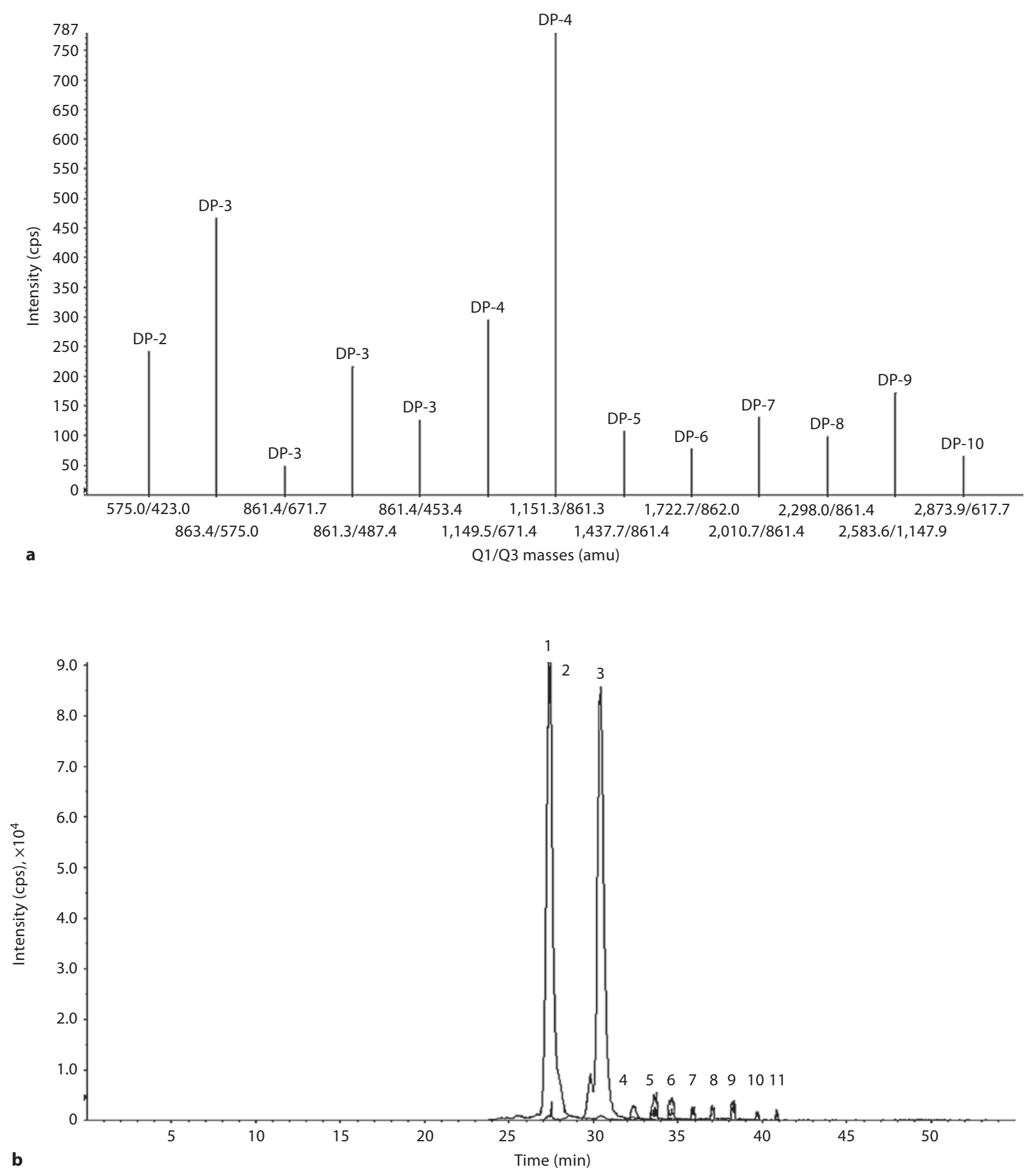

Fig. 1. MRM chromatogram of oligomeric PAC in the cranberry PAC fraction tested in this study. DP = Degree of polymerization. a Product ions from DP-2 to DP-10. Y axis: peak intensity as counts per second. X axis: mass for product ion in MRM mode as Q1/Q3. b An example of total ion chromatogram in MRM mode representing peaks 1 to 11 . Y axis: intensity of peaks in counts per second. $\mathrm{X}$ axis: time/min. Peaks 1 and 2 represent dimers, 3-5 trimers, 6-7 tetramers, 8-9 pentamers, 10 a hexamer and 11 a heptamer. DP-8 to DP-10 are not shown. 
nol in water $(\mathrm{v} / \mathrm{v})$ to selectively separate monomers to tetramers, dimers to pentamers, soluble tannins and DP-4 to DP-6, DP-7 to DP-9, DP-8 to DP-12 and, finally, high-molecular DP ( $\geq$ DP-12). The various fractions obtained from both column chromatograms containing different cutoff weights of oligomer-ic PAC based on the MALDI-TOF-MS spectrum were applied to HPLC separation using a diol column; epicatechin (monomer), procyanidin $\mathrm{A}_{2}$ (dimers), trimers, tetramers and specific fractions of PAC (DP-4-6, 7-9, 9-12 and >12) were then obtained and dried using a rotavapor under reduced temperature and pressure $\left(35^{\circ} \mathrm{C}\right)$ for the bioassays in vitro.

\section{Effects of PAC Isolates on GtfB Activity}

The GtfB enzymes (E.C. 2.4.1.5) were prepared from culture supernatants and purified to near homogeneity by hydroxyapatite column chromatography as described by Koo et al. [2000]. Gtf activity was measured by the incorporation of $\left[{ }^{14} \mathrm{C}\right]$ glucose from labeled sucrose (NEN Research Products, Boston, Mass., USA) into glucans. The Gtf enzyme added to each sample for all assays was equivalent to the amount required to incorporate $1-1.5 \mu \mathrm{mol}$ of glucose over the 4-hour reaction (1.0-1.5 U).

The activity of GtfB was determined by the enzymes in solution or adsorbed to hydroxyapatite beads (Macro-Prep Ceramic Hydroxyapatite Type I; $80 \mu \mathrm{m}$; Bio- $\operatorname{Rad}^{\circledR}$ ) coated with clarified whole saliva (sHA; free of Gtf activity), in the presence of test agents $(0.1 \mathrm{mg} / \mathrm{ml})$ or the vehicle control (15\% ethanol and $2.5 \%$ DMSO) as described elsewhere [Koo et al., 2000]; a higher concentration of ethanol and the addition of DMSO were necessary to dissolve some of the PAC, especially epicatechin and procyanidin $\mathrm{A}_{2}$. The final $\mathrm{pH}$ of the reaction mixture was approximately 6.5 , which is within the optimum $\mathrm{pH}$ of $\mathrm{GtfB}$ either in solution or adsorbed on the surface [Schilling et al., 1988].

\section{Effects of PAC Isolates on Glycolytic pH Drop by S. mutans}

The effects of the cranberry PAC on glycolysis were measured by standard $\mathrm{pH}$ drop using dense cell suspensions as previously described by Belli et al. [1995]. Cells of S. mutans UA159 from suspension cultures were harvested, washed once with salt solution (50 $\mathrm{mM} \mathrm{KCl}$ plus $1 \mathrm{mM} \mathrm{MgCl}_{2} ; \mathrm{pH} \mathrm{7.0)}$ and resuspended in salt solution containing the test agents $(0.1 \mathrm{mg} / \mathrm{ml})$ or vehicle control. Glucose was added to the mixture to give a final concentration of $1 \%(\mathrm{w} / \mathrm{v})$, and the decrease in $\mathrm{pH}$ was assessed by means of a glass electrode (Futura Micro Combination $\mathrm{pH}$ electrode) over a period of $60 \mathrm{~min}$.

\section{Animal Studies}

The animal experiment was performed using methods previously described [Bowen et al., 1988; Koo et al., 2005]. Female Sprague-Dawley rats aged 14 days were purchased with their dams from Harlan Inc. (Indianapolis, Ind., USA). The dams, while still nursing, were infected by mouth with an actively growing culture of S. mutans UA159 [Bowen et al., 1988; Yamashita et al., 1993], and reinfected the next day. The animals were fed Diet 2000 (56\% sucrose; Ziegler Bros., Gardners, Pa., USA) and offered $5 \%$ sucrose water to drink ad libitum to enhance the infection by S. mutans. At the age of 21 days, the pups were weaned and their infection checked. The animals were then randomly placed into 3 groups of 16 animals, and their teeth treated topically using a camel's hair brush twice daily as follows: (1) PAC $(1.5 \mathrm{mg} / \mathrm{ml}$ in $10 \%$ ethanol, v/v); (2) $250 \mathrm{ppm}$ of $\mathrm{F}$ (as positive control), or (3) ve- hicle control (10\% ethanol, v/v; as negative control). The animals were provided with Diet 2000 and 5\% sucrose water ad libitum [Bowen et al., 1988; Koo et al., 2005]. The experiment proceeded for 5 weeks, and all animals were weighed weekly and their physical appearance noted daily. At the end of the experimental period, the rats were sacrificed by $\mathrm{CO}_{2}$ asphyxiation. The left jaw was aseptically dissected and sonicated in $5.0 \mathrm{ml}$ of $154 \mathrm{mM}$ sterile $\mathrm{NaCI}$ solution. The suspensions obtained were streaked on mitis salivarius agar (Difco) plus bacitracin (Sigma) to estimate the S. mutans population, and on blood agar (blood agar base plus $5 \%$ sheep blood) to determine the total cultivable flora [Bowen et al., 1988]. All of the jaws were defleshed, and the teeth prepared for caries scoring by means of Larson's modification of Keyes' system [Larson, 1981]. The determination of the caries score was blinded by codification of the jaws and was done by 1 calibrated examiner. This study was reviewed and approved by the University of Rochester Committee on Animal Resources (UCAR No. 2003-124; University of Rochester Medical Center, Rochester, N.Y., USA).

\section{Statistical Analyses}

For the in vitro studies, an exploratory data analysis was performed to determine the most appropriate statistical test; the assumptions of equality of variances and normal distribution of errors were also checked. The data were then analyzed using ANOVA, and the F test was used to test any difference between the groups. When significant differences were detected, a pairwise comparison was made between all the groups using Tukey's method to adjust for multiple comparisons. For the animal study, an analysis of outcome measures was done with transformed values of the measures in order to stabilize variances as detailed in Raubertas et al. [1999]; smooth-surface and sulcal caries scores were expressed as proportions of their maximum possible values (124 and 56, respectively), and the arcsine transformation was applied. The data were then subjected to ANOVA in the TukeyKramer Honest Standard Deviation (HSD) test for all pairs. The statistical software JMP, version 3.1 (SAS Institute, Cary, N.C., USA), was used to perform the analyses. The level of significance was set at $5 \%$.

\section{Results}

The purified PAC fraction tested in this study consisted of a mixture of low-molecular-weight epicatechin (monomer) and oligomers ranging from dimers (procyanidin $\mathrm{A}_{2}$ ) to high-molecular-weight oligomers ranging in DP of 3-10 largely epicatechin units, as well as larger high-molecular-weight polymers (DP of $>10)$ (fig. 1). The fraction contained a higher percentage of dimers $(8.0 \%)$, trimers $(16.6 \%)$, tetramers $(20.7 \%)$, pentamers $(2.5 \%)$, octamers (4.0\%), nonamers (6.0\%), decamers (6.3\%) and pentadecamers (3.6\%) than monomers (less than $0.01 \%$ ) and other oligomeric PAC (total combined: $32.9 \%$ ) based on relative percentage (percent by weight), and were devoid of any other phenolic (e.g. phenolic acids, flavonols and anthocyanins) and sugar contaminants. 


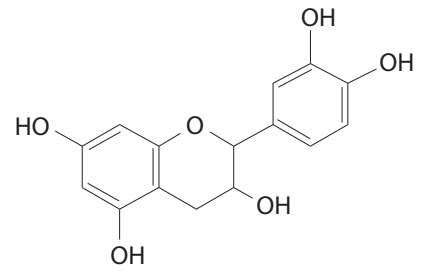

Epicatechin

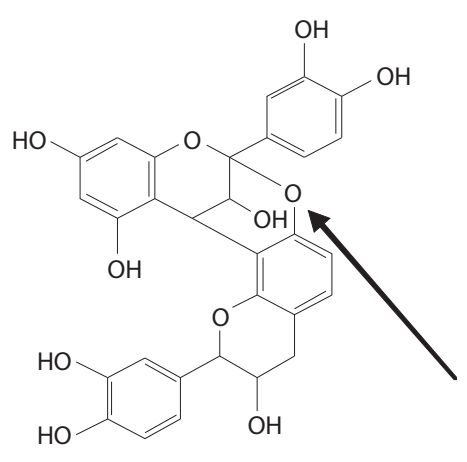

A-type double interflavan bond

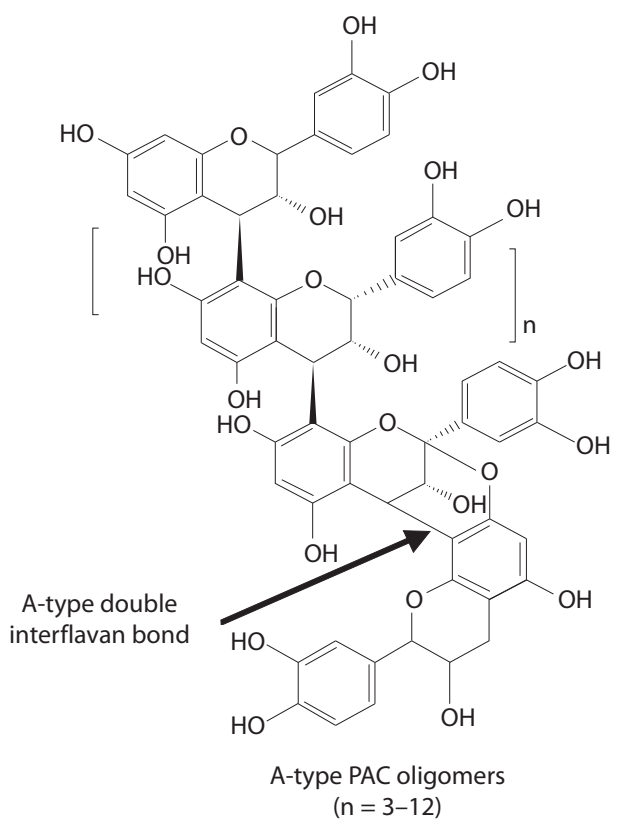

Epicatechin- $(4 \beta \rightarrow 8)$-epicatechin (procyanidin $\mathrm{A}_{2}$ )

Fig. 2. Chemical structures of the PAC isolated from cranberry.

Table 1. S. mutans UA159 biofilm composition after treatments ${ }^{1}$

\begin{tabular}{|c|c|c|c|}
\hline & $\begin{array}{l}\text { Vehicle } \\
\text { control }\end{array}$ & $\begin{array}{l}\text { PAC } \\
(1.5 \mathrm{mg} / \mathrm{ml})\end{array}$ & $\begin{array}{l}250 \text { ppm } \\
\text { fluoride }\end{array}$ \\
\hline Dry weight, mg & $5.6(0.4)^{\mathrm{a}}$ & $3.4(0.2)^{\mathrm{b}}$ & $4.6(0.3)^{\mathrm{c}}$ \\
\hline Insoluble glucans, mg & $2.3(0.2)^{\mathrm{a}}$ & $1.5(0.1)^{\mathrm{b}}$ & $1.9(0.2)^{\mathrm{a}, \mathrm{b}}$ \\
\hline IPS, mg & $0.22(0.05)^{\mathrm{a}}$ & $0.24(0.05)^{\mathrm{a}}$ & $0.12(0.04)^{b}$ \\
\hline $\begin{array}{c}\mathrm{pH}(240 \text { min after } \\
\text { treatment })^{2}\end{array}$ & $5.2(0.1)^{\mathrm{a}}$ & $5.6(0.2)^{\mathrm{b}}$ & $6.0(0.1)^{\mathrm{c}}$ \\
\hline
\end{tabular}

Values $(\mathrm{n}=12)$ are means with SD in parentheses. Values followed by the same superscripts are not significantly different from each other ( $\mathrm{p}>0.05$; ANOVA; comparison for all pairs using Tukey's test). IPS = Intracellular polysaccharides.

${ }^{1}$ Twice daily with 1-min exposure to each treatment.

${ }^{2}$ The initial $\mathrm{pH}$ of the culture medium was $7.2 \pm 0.1$. The $\mathrm{pH}$ values at 60 and $120 \mathrm{~min}$ were not significantly different from each other $(p>0.05)$.

The topical applications of PAC (1-min exposure, twice daily) significantly reduced the biomass (dry weight) and total amount of extracellular insoluble polysaccharides of S. mutans biofilms (35-40\% reduction) compared with the vehicle control (10\% ethanol, v/v) treatments $(\mathrm{p}<0.05)$ (table 1); however, the PAC did not affect the accumulation of intracellular polysaccharides in the biofilms. Fluoride at $250 \mathrm{ppm}$ also showed inhibitory effects on the biomass, and especially on the amounts of intracellular polysaccharides in the treated biofilms (vs. vehicle control; $p<0.05$ ). Furthermore, all test agents significantly reduced the acidogenicity of the biofilms, as indicated by higher $\mathrm{pH}$ values of the surrounding medium (at $240 \mathrm{~min}$ after initial treatment) (table 1) compared with those of the vehicle-treated biofilms $(p<0.05)$. The number of viable cells, and the amount of protein and soluble polysaccharides in the biofilms treated with the test agents did not differ statistically from that of the vehicle-treated biofilms ( $p>0.05$; data not shown).

The chemical structures and the bioactivity of individual low- and high-molecular-weight cranberry PAC are shown in figure 2 and table 2. In general, the PAC with the exception of epicatechin (monomer) - were highly effective inhibitors of GtfB activity either in solution or adsorbed on the sHA surface. Clearly, PAC with a DP of 4-12 were potent inhibitors of the activity of surface-adsorbed GtfB (40-70\% inhibition). In contrast, the PAC oligomers (DP of $>3$ ) showed modest effects on acid 
Table 2. Biological activity of isolated cranberry PAC

\begin{tabular}{llll}
\hline Agents & $\begin{array}{l}\text { GtfB in } \\
\text { solution }\end{array}$ & $\begin{array}{l}\text { GtfB on } \\
\text { surface }\end{array}$ & $\begin{array}{l}\text { Inhibition } \\
\text { of acid } \\
\text { production }^{1}\end{array}$ \\
\hline Epicatechin (monomer) & $18.2(2.9)$ & - & - \\
Procyanidin A (dimer) & $15.8(3.5)$ & $27.6(6.3)$ & ++ \\
A-type PAC trimers & $77.5(2.1)$ & $29.4(3.6)$ & + \\
A-type PAC tetramers & $78.0(1.6)$ & $36.7(5.1)$ & + \\
PAC extract (DP-4 to DP-6) & $84.8(1.4)$ & $52.4(5.5)$ & + \\
PAC extract (DP-7 to DP-9) & $91.5(1.1)$ & $69.5(4.5)$ & + \\
PAC extract (DP-9 to DP-12) & $94.5(3.2)$ & $53.5(7.5)$ & + \\
PAC extract (>DP-12) & $54.4(1.5)$ & $42.6(2.1)$ & + \\
\hline
\end{tabular}

Values denote mean percentages of inhibition with SD in parentheses. The percentages were calculated considering the vehicle control as the maximum GtfB activity $(n=6)$. None of the test agents were bactericidal against $S$. mutans.

${ }^{1}$ Based on $\Delta \mathrm{pH}$ measurement $\left(\mathrm{pH}_{\text {test agent }}-\mathrm{pH}_{\text {control }}\right.$ at 30 or 60 min after glucose pulse; $\mathrm{n}=6) .+=\Delta \mathrm{pH} 0.1-0.2 ;++=\Delta \mathrm{pH}$ $\geq 0.21$; $-=$ no significant effect (the values were not significantly different from vehicle control; $\mathrm{p}>0.05$; ANOVA; comparison for all pairs using Tukey's test).

production; procyanidin $\mathrm{A}_{2}$ was the most effective agent against $S$. mutans acidogenicity. None of the PAC displayed antibacterial (biocidal) activity at concentrations tested in this study.

In the animal experiment, the rats remained in apparent good health during the 5-week experiment; weight gains were not significantly different among the vehicle control and test agent groups ( $\mathrm{p}>0.05)$. The incidence and severity of smooth-surface caries were significantly reduced in the groups treated with PAC and $250 \mathrm{ppm}$ of F (twice daily) compared with the vehicle controls ( $\mathrm{p}<$ 0.05) (table 3) despite negligible effects on the counts of both the total and $S$. mutans populations recovered from the animal's plaque (vs. control; $\mathrm{p}>0.05$; data not shown). The PAC treatments resulted in $40-45 \%$ less severe smooth-surface lesions than the vehicle control treatment (at Dm, 3/4 of the dentin affected, and Dx, whole dentin affected, levels; $\mathrm{p}<0.05$ ). The groups treated with $250 \mathrm{ppm}$ of $\mathrm{F}$ (positive control) had significantly less smooth-surface caries and less severe lesions than those treated with PAC $(\mathrm{p}<0.05)$. The incidence and severity of sulcal-surface caries (at the Ds, dentin exposed, level) were significantly reduced only in the groups treated with $250 \mathrm{ppm}$ of $\mathrm{F}(\mathrm{p}<0.05)$ (table 4). However, the sulcalsurface caries severity scores at the Dm and Dx levels were reduced by both PAC and 250-ppm F treatments when compared to the vehicle control group $(p<0.05)$.
Table 3. Effects of treatments on development (smooth-surface and severity) of dental caries in rats (Keyes' score)

\begin{tabular}{llll}
\hline & $\begin{array}{l}\text { Vehicle } \\
\text { control }\end{array}$ & $\begin{array}{l}\text { PAC } \\
(1.5 \mathrm{mg} / \mathrm{ml})\end{array}$ & $\begin{array}{l}250 \mathrm{ppm} \\
\text { fluoride }\end{array}$ \\
\hline $\begin{array}{l}\text { Smooth-surface caries } \\
\begin{array}{l}\text { Smooth-surface severity } \\
\text { Ds }\end{array}\end{array}$ & $55.7(15.8)^{\mathrm{a}}$ & $53.1(12.9)^{\mathrm{b}}$ & $31.1(10.3)^{\mathrm{c}}$ \\
Dm & $55.6(16.2)^{\mathrm{a}}$ & $40.8(13.1)^{\mathrm{b}}$ & $9.6(5.6)^{\mathrm{c}}$ \\
Dx & $39.2(16.1)^{\mathrm{a}}$ & $23.1(10.3)^{\mathrm{b}}$ & $3.2(3.5)^{\mathrm{c}}$ \\
\hline
\end{tabular}

Values denote means with SD in parentheses $(n=16)$. Values followed by the same superscripts are not significantly different from each other ( $\mathrm{p}<0.05$; ANOVA; comparison for all pairs using the Tukey-Kramer HSD). Ds = Dentin exposed; Dm $=3 / 4$ of the dentin affected; $\mathrm{Dx}=$ whole dentin affected.

Table 4. Effects of treatments on development (sulcal-surface caries and severity) of dental caries in rats (Keyes' score)

\begin{tabular}{llll}
\hline & $\begin{array}{l}\text { Vehicle } \\
\text { control }\end{array}$ & $\begin{array}{l}\text { PAC } \\
(1.5 \mathrm{mg} / \mathrm{ml})\end{array}$ & $\begin{array}{l}\text { 250 ppm } \\
\text { fluoride }\end{array}$ \\
\hline $\begin{array}{l}\text { Sulcal-surface caries } \\
\text { Sulcal-surface severity }\end{array}$ & $52.9(2.1)^{\mathrm{a}}$ & $51.1(2.6)^{\mathrm{a}}$ & $40.4(9.5)^{\mathrm{b}}$ \\
$\quad$ Ds & $45.4(1.7)^{\mathrm{a}}$ & $43.4(2.7)^{\mathrm{a}}$ & $35.2(8.2)^{\mathrm{b}}$ \\
Dm & $33.7(6.5)^{\mathrm{a}}$ & $25.0(5.8)^{\mathrm{b}}$ & $12.1(7.2)^{\mathrm{c}}$ \\
Dx & $24.3(6.7)^{\mathrm{a}}$ & $17.1(7.4)^{\mathrm{b}}$ & $5.1(5.4)^{\mathrm{c}}$ \\
\hline
\end{tabular}

Values denote means with SD in parentheses $(n=16)$. Values followed by the same superscripts are not significantly different from each other $(p<0.05$; ANOVA; comparison for all pairs using the Tukey-Kramer HSD).

\section{Discussion}

PAC are polymers of flavan-3-ols, having a common C6-C3-C6 flavone skeleton. In cranberry, PAC polymers are built upon monomers of epicatechin, and are predominantly found in oligomeric (up to 10 monomeric units) and polymeric forms ( $>10$ units, known as condensed tannins) with at least 1 A-type double interflavan linkage (fig. 2); A-type PAC are uniquely found in high concentrations in cranberry, and have been shown to be biologically active [Cunningham et al., 2004]. PAC at 1.5 $\mathrm{mg} / \mathrm{ml}$ was selected based on data from our previously published and unpublished response-to-dose studies, and is within the concentration normally found in cranberry juice and extracts [Cunningham et al., 2004; 
Duarte et al., 2006; Koo et al., 2006]. Although our monospecies biofilm model does not mimic exactly the complex microbial community found in coronal dental plaque, it does however place emphasis on a critical virulence characteristic of the biofilm, i.e. the polysaccharide matrix. Furthermore, biofilms using a single organism are advantageous in examining the mechanisms of actions of therapeutic agents on S. mutans physiology, especially on the glucan-mediated processes involved in the formation of the polysaccharide matrix in biofilm.

In this study, we demonstrated that a highly purified A-type PAC fraction reduced the formation of biofilms by $S$. mutans on saliva-coated apatitic surface, which correlated well with a reduction in the amounts of insoluble polysaccharides in the extracellular matrix. The insoluble exopolysaccharides (mostly insoluble glucans rich in 3-linked glucose) are essential for the adherence, coherence and accumulation of microorganisms on the tooth surface, and provide bulk and structural integrity to the biofilms' matrix [Paes Leme et al., 2006; Xiao and Koo, 2009]. Despite the lack of significant antibacterial (biocidal) activity, PAC treatments diminished the acidogenicity of $S$. mutans within biofilms likely by disrupting the overall bacterial metabolism. The reduction in insoluble glucans in the biofilms is consistent with the effective inhibition of Gtf (especially GtfB and GtfC) observed previously using cranberry juice and a crude extract containing an unknown mixture of PAC [Koo et al., 2006; Duarte et al., 2006]. The exact mechanisms by which cranberry PAC acts to inhibit Gtf activity are currently unknown, and may be related to their unique structural characteristics. The presence of A-type linkage (which confers rigidity to the molecule) and the DP may be associated with the biological activity of cranberry PAC, including the inhibition of Gtf [Gregoire et al., 2007]. For example, PAC from other fruits that lack A-type linkage are without effect on Gtf enzymes, whereas PAC larger than trimers (DP of $>3$ ) are more effective Gtf inhibitors than monomers and dimers [Yanagida et al., 2000; Osawa et al., 2001]. It is likely that PAC are noncompetitive inhibitors based on our previous studies with other polyphenolic compounds [Koo et al., 2002; Murata et al., 2008]. PAC have shown to bind proteins, forming protein-polyphenol complexes [Haslam, 1996] which can affect the enzyme activity by irreversibly binding to the catalytic domain, glucan-binding domain and/or other sites once complexed. The protein-binding capacity of PAC is a function of DP, access to the proteins and the type of interflavan linkage [Foo et al., 2000; Gregoire et al., 2007; Delehanty et al., 2007].

Cranberry Proanthocyanidins on

S. mutans Cariogenicity
The PAC fraction from cranberry extract consisted of an array of largely epicatechin oligomers ranging in DP from 2 to over 10. Therefore, we examined purified individual compounds and fractions having specific DP ranges of high-molecular-weight $\mathrm{PAC}$, with the intent to identify precisely the constituents that are associated with the bioactivity of cranberry PAC extract. In general, the inhibitory activity of PAC enhanced when the DP increased from 2 to 12 monomeric units. However, a further increase in DP did not increase but actually diminished the Gtf inhibition activity of PAC. It is apparent that PAC with a DP ranging from 4 to 12 are optimal to effectively inhibit surface-adsorbed GtfB (40-70\% inhibition at $0.1 \mathrm{mg} / \mathrm{ml}$ ). Approximately $60 \%$ of the PAC fraction used in this study is comprised of A-type dimers through dodecamers; clearly, these are major bioactive compounds in cranberries. Further studies using individual PAC oligomers to determine the enzyme-binding sites and kinetics, and the effects on glucan structure, shall elucidate in more detail the structure-activity relationships (e.g. the role of DP and A-type linkage) associated with Gtf inhibition. In addition, an analysis of the effects on fructosyltransferase, which catalyzes a similar reaction but involves distinct monomeric units and glycosidic linkages, would contribute to a better understanding of the mechanisms of action of PAC.

The influences of the PAC fraction on the acidogenicity of $S$. mutans biofilms may be associated with the presence of procyanidin $\mathrm{A}_{2}$ (despite some inhibitory effects caused by oligomers). Recently, we have shown that procyanidin $\mathrm{A}_{2}$, a low-molecular-weight PAC dimer, disrupted both the acid production and acid tolerance of $S$. mutans cells as determined by glycolytic $\mathrm{pH}$ drop experiments, and partially inhibited the activity of membrane-associated F-ATPases [Gregoire et al., 2007]. In contrast, it is unlikely that larger PAC oligomers will directly affect the intracellular enzymes involved in the bacterial glycolysis. Nevertheless, it has been shown that PAC oligomers bind to bacterial membrane, and there is a correlation between binding properties with the presence of the A-type linkage and DP [Foo et al., 2000; Delehanty et al., 2007]. Cranberry PAC oligomers with a DP of 4 and 5, containing at least 1 A-type bond, displayed strong membrane-binding activity in Escherichia coli [Foo et al., 2000]. Thus, the oligomers may cause deleterious effects on acidogenicity by affecting the membrane components of the glycolytic pathway of S. mutans; our data, however, did not show a correlation between DP and effects on glycolytic $\mathrm{pH}$ drop.

Caries Res 2010;44:116-126 
In the last step of the study, we examined whether the antibiofilm activities of cranberry PAC observed in vitro would be translated into cariostatic effects in vivo, using a well-established rodent model of dental caries [Bowen et al., 1988; Koo et al., 2005]. The in vivo model simulates more precisely the variables encountered in the oral cavity such as exposure to salivary and cellular components, as well as hydrodynamic and abrasive forces. The presence of saliva is particularly important considering that salivary proteins (especially proline-rich proteins) are known to bind polyphenols [Bennick, 2002]. Furthermore, the rat harbors a complex and mixed oral flora even though it is infected by $S$. mutans. Daily exposure to the PAC fraction significantly disrupted the development of smooth-surface caries and, to a lesser extent, sulcalsurface carious lesions. The cariostatic effects of the topical application of PAC (30-second exposure, twice daily) to the animal's mouth indicates that the active compounds are available at efficacious concentrations (despite the brief exposure and clearance of the agents in the oral cavity) when a sucrose-rich diet is ingested by the animals. The persistence of a therapeutic effect of a topically applied agent in the oral cavity is a highly desirable property in developing chemotherapeutic approaches to plaque-related oral diseases such as dental caries [Brecx et al., 1997]. The anticaries mechanisms of the PAC fraction may be related, in part, to their effective inhibition of surface-adsorbed GtfB and GtfC activities in addition to inhibitory effects on bacterial glycolysis [Duarte et al., 2006], which would attenuate the pathogenicity of $S$. mutans in vivo. This observation could be attributed to the presence of specific low- (dimers) and high-molecularweight bioactive PAC oligomers (tetramers to dodecamers) in the extract. Earlier studies have shown that the deletion of genes controlling the production of Gtf, especially $g t f B$ and $g t f C$, resulted in a dramatic decline in the virulence of $S$. mutans in vivo [Tanzer et al., 1985; Yamashita et al., 1993]. PAC were more effective in reducing the development of carious lesions on the smooth surface than on the sulcal surface (table 1). The data are consistent with a marked reduction in smooth-surface caries (but showing a less pronounced effect on the incidence of sulcal caries) observed in rats infected with mutants of mutans streptococci defective in the production of either one or both Gtf [Tanzer et al., 1985; Yamashita et al., 1993].

Treatment with PAC extract alone was not as effective as our positive control ( $250 \mathrm{ppm}$ of $\mathrm{F}$ ) in reducing caries development. Fluoride at $225-250 \mathrm{ppm}$ is a clinically proven anticaries agent, and is the concentration found in most of the currently commercially available fluoridebased mouth rinses [Zero, 2006]. However, the overall cariostatic effects of PAC and fluoride may be enhanced without increasing the concentration of exposure when used in combination because fluoride, at micromolar levels found in plaque matrix, disrupts the insoluble glucan synthesis and acidogenicity of $S$. mutans in biofilms [Koo et al., 2008]. Further studies using individual oligomers and multispecies biofilm models in the presence of saliva shall elucidate the biological effects on complex ecologyhost interactions and their influences on the EPS matrix development, which will advance our understanding of the exact mechanisms of action of these compounds. Moreover, additional response-to-dose studies on each of these oligomers and the inclusion of fluoride may provide an optimized combination of agents displaying enhanced therapeutic activity in vivo.

Standardization and characterization of natural products are key factors for a successful development of alternative, effective and useful therapeutic approaches to reduce or prevent human diseases [Schmidt et al., 2007]. In this context, cranberries are feasible and sustainable source of naturally occurring bioactive compounds because (1) cranberry is a chemically and genetically wellcharacterized fruit which can ensure a highly standardized source for PAC extraction, and (2) the cultivation procedures and PAC content profile during fruit development and maturation are well established, which is critical to determine the optimum harvest time for the highest PAC yield. Clearly, cranberry PAC show promise for the development of novel alternative or adjunctive anticaries chemotherapy.

\section{Acknowledgments}

The authors thank Dr. William H. Bowen for his critical reading of the manuscript, and Mr. Graham Gibson (Applied Biosystems) for his gift of the API-3000 LC-MS-MS instrument.

This research was supported by grants from the National Institute for Dental and Craniofacial Research (1R01DE016139-01; H.K.), the National Center for Complementary and Alternative Medicine (5R01AT002058; N.V.) and the Brazilian Government Agency - CAPES Foundation Grant BEX 0154/06-7 (scholarship to R.M.M.). 


\section{References}

Ajdić D, McShan WM, McLaughlin RE, Savić G, Chang J, Carson MB, Primeaux C, Tian R, Kenton S, Jia H, Lin S, Qian Y, Li S, Zhu H, Najar F, Lai H, White J, Roe BA, Ferretti JJ: Genome sequence of Streptococcus mutans UA159, a cariogenic dental pathogen. Proc Natl Acad Sci USA 2002;99:14434-14439.

-Belli WA, Buckley DH, Marquis RE: Weak acid effects and fluoride inhibition of glycolysis by Streptococcus mutans GS-5. Can J Microbiol 1995;41:785-791.

- Bennick A: Interaction of plant polyphenols with salivary proteins. Crit Rev Oral Biol Med 2002;13:184-196.

Bowen WH: Do we need to be concerned about dental caries in the coming millennium? Crit Rev Oral Biol Med 2002;13:126-131.

Bowen WH, Madison KM, Pearson SK: Influence of desalivation in rats on incidence of caries in intact cagemates. J Dent Res 1988; 67:1316-1318.

Brecx M: Strategies and agents in supragingival chemical plaque control. Periodontol 2000 1997; 15:100-108.

-Cegelski L, Marshall GR, Eldridge GR, Hultgren SJ: The biology and future prospects of antivirulence therapies. Nat Rev Microbiol 2008; 6:17-27.

Cunningham DG, Vannozzi SA, Turk R, O’Shea E, Brilliant K: Cranberry phytochemicals and their health benefits; in Shahidi F, Weerasinghe DK (eds): Nutraceutical Beverages. Chemistry, Nutrition, and Health Effects. ACS Symposium Series 871. Washington, American Chemical Society, 2004, pp 35-50.

-Delehanty JB, Johnson BJ, Hickey TE, Pons T, Ligler FS: Binding and neutralization of lipopolysaccharides by plant proanthocyanidins. J Nat Prod 2007;70:1718-1724.

-DiPersio JR, Mattingly SJ, Higgins ML, Shockman GD: Measurement of intracellular iodophilic polysaccharide in two cariogenic strains of Streptococcus mutans by cytochemical and chemical methods. Infect Immun 1974;10:597-604.

- Duarte S, Gregoire S, Singh AP, Vorsa N, Schaich $\mathrm{K}$, Bowen WH, Koo H: Inhibitory effects of cranberry polyphenols on formation and acidogenicity of Streptococcus mutans biofilms. FEMS Microbiol Lett 2006;257:50-56.

Duarte S, Klein MI, Aires CP, Cury JA, Bowen $\mathrm{WH}, \mathrm{Koo} \mathrm{H}$ : Influences of starch and sucrose on Streptococcus mutans biofilms. Oral Microbiol Immunol 2008;23:206-212.

-Dubois M, Gilles KA, Hamilton JK, Rebers PA, Smith F: Colorimetric method for determination of sugars and related substances. Anal Chem 1956;28:350-356.

Emilson CG, Nilsson B, Bowen WH: Carbohydrate composition of dental plaque from primates with irradiation caries. J Oral Pathol 1984;13:213-220.

Flemming HC, Neu TR, Wozniak DJ: The EPS matrix: the 'house of biofilm cells'. J Bacteriol 2007;189:7945-7947.
Foo LY, Lu Y, Howell AB, Vorsa N: The structure of cranberry proanthocyanidins which inhibit adherence of uropathogenic P-fimbriated Escherichia coli in vitro. Phytochemistry 2000;54:173-181.

Gibbons RJ: Adherent interactions which may affect microbial ecology in the mouth. J Dent Res 1984;63:378-385.

Gregoire S, Singh AP, Vorsa N, Koo H: Influence of cranberry phenolics on glucan synthesis by glucosyltransferases and Streptococcus mutans acidogenicity. J Appl Microbiol 2007; 103:1960-1968.

Guggenheim B: Extracellular polysaccharides and microbial plaque. Int Dent J 1970;20: 657-678.

Hamada S, Slade HD: Biology, immunology, and cariogenicity of Streptococcus mutans. Microbiol Rev 1980;44:331-384.

-Haslam E: Natural polyphenols (vegetable tannins) as drugs: possible modes of action. J Nat Prod 1996;59:205-215.

-Hayacibara MF, Koo H, Vacca Smith AM, Kopec LK, Scott-Anne K, Cury JA, Bowen WH: The influence of mutanase and dextranase on the production and structure of glucans synthesized by streptococcal glucosyltransferases. Carbohydr Res 2004;12:2127-2137.

Hotz P, Guggenheim B, Schmid R: Carbohydrates in pooled dental plaque. Caries Res 1972;6:103-121.

Koo H: Strategies to enhance the biological effects of fluoride on dental biofilms. Adv Dent Res 2008;20:17-21.

Koo H, Hayacibara MF, Schobel BD, Cury JA, Rosalen PL, Park YK, Vacca Smith AM, Bowen WH: Inhibition of Streptococcus mutans biofilm accumulation and polysaccharide production by apigenin and $t t$-farnesol. J Antimicrob Chemother 2003;52:782-789.

Koo H, Nino de Guzman P, Schobel BD, Vacca Smith AV, Bowen WH: Influence of cranberry juice on glucan-mediated processes involved in Streptococcus mutans biofilm development. Caries Res 2006;40:20-27.

Koo H, Rosalen PL, Cury JA, Park YK, Bowen WH: Effects of compounds found in propolis on Streptococcus mutans growth and on glucosyltransferase activity. Antimicrob Agents Chemother 2002;46:1302-1309.

Koo H, Schobel B, Scott-Anne K, Watson G, Bowen WH, Cury JA, Rosalen PL, Park YK: Apigenin and $t t$-farnesol with fluoride effects on $S$ mutans biofilms and dental caries. J Dent Res 2005;84:1016-1020.

Koo H, Vacca Smith AM, Bowen WH, Rosalen PL, Cury JA, Park YK: Effects of Apis mellifera propolis on the activities of streptococcal glucosyltransferases in solution and adsorbed onto saliva-coated hydroxyapatite. Caries Res 2000;34:418-426.

Kopec LK, Vacca Smith AM, Bowen WH: Structural aspects of glucans formed in solution and on the surface of hydroxyapatite. Glycobiology 1997;7:929-934.
La VD, Howell AB, Grenier D: Cranberry proanthocyanidins inhibit MMP production and activity. J Dent Res 2009;88:627-632.

Larson RM: Merits and modifications of scoring rat dental caries by Keyes' method; in Tanzer JM (ed): Animal Models in Cariology. Microbiology Abstracts (special suppl.). Washington, IRL, 1981, pp 195-203.

Marquis RE, Clock SA, Mota-Meira M: Fluoride and organic weak acids as modulators of microbial physiology. FEMS Microbiol Rev 2003;760:1-18.

Marsh PD: Are dental diseases examples of ecological catastrophes? Microbiology 2003; 149:279-294.

Moore S, Stein WH: A modified ninhydrin reagent for the photometric determination of amino acids and related compounds. J Biol Chem 1954;211:907-913.

Murata RM, Branco de Almeida LS, Yatsuda R, Dos Santos MH, Nagem TJ, Rosalen PL, Koo $\mathrm{H}$ : Inhibitory effects of 7-epiclusianone on glucan synthesis, acidogenicity and biofilm formation by Streptococcus mutans. FEMS Microbiol Lett 2008;282:174-181.

- Osawa K, Miyazaki K, Shimura S, Okuda J, Matsumoto M, Ooshima T: Identification of cariostatic substances in the cacao bean husk: their anti-glucosyltransferase and antibacterial activities. J Dent Res 2001;80:20002004.

Paes Leme AF, Koo H, Bellato CM, Bedi G, Cury JA: The role of sucrose in cariogenic dental biofilm formation: new insight. J Dent Res 2006;85:878-887.

- Quivey RG Jr, Kuhnert WL, Hahn K: Adaptation of oral streptococci to low $\mathrm{pH}$. Adv Microb Physiol 2000;42:239-274.

-Raubertas RF, Davis BA, Bowen WH, Pearson SK, Watson GE: Litter effects on caries in rats and implications for experimental design. Caries Res 1999;33:164-169.

Reese S, Guggenheim B: A novel TEM contrasting technique for extracellular polysaccharides in in vitro biofilms. Microsc Res Tech 2007:70:816-822.

Rölla G, Ciardi JE, Eggen K, Bowen WH, Afseth $\mathrm{J}$ : Free glucosyl- and fructosyltransferase in human saliva and adsorption of these enzymes to teeth in vivo; in Doyle RJ, Ciardi JE (eds): Glucosyltransferases, Glucans, Sucrose, and Dental Caries. Washington, Chemical Senses, 1983, pp 21-30.

Schilling KM, Bowen WH: The activity of glucosyltransferase adsorbed onto saliva-coated hydroxyapatite. J Dent Res 1988;67:2-8.

Schilling KM, Bowen WH: Glucans synthesized in situ in experimental salivary pellicle function as specific binding sites for Streptococcus mutans. Infect Immun 1992;60:284-295.

Schmidt BM, Ribnicky DM, Lipsky P, Raskin I: Revisiting the ancient concept of botanical therapeutics. Nat Chem Biol 2007;3:360366. 
- Singh AP, Singh RK, Kim KK, Satyan KS, Nussbaum R, Torres M, Brard L, Vorsa N: Cranberry proanthocyanidins are cytotoxic to human cancer cells and sensitize platinumresistant ovarian cancer cells to paraplatin. Phytother Res 2009;23:1066-1074.

-Steinberg D, Rozen R, Bromshteym M, Zaks B, Gedalia I, Bachrach G: Regulation of fructosyltransferase activity by carbohydrates, in solution and immobilized on hydroxyapatite surfaces. Carbohydr Res 2002;337:701-710.

Tanzer JM, Freedman ML, Fitzgerald RJ: Virulence of mutants defective in glucosyltransferase, dextran-mediated aggregation, or dextranase activity; in Mergenhagen SE, Rosan B (eds): Molecular Basis of Oral Microbial Adhesion. Washington, American Society for Microbiology, 1985, pp 204-211.
Vacca Smith AM, Bowen WH: Binding properties of streptococcal glucosyltransferases for hydroxyapatite, saliva-coated hydroxyapatite, and bacterial surfaces. Arch Oral Biol 1998;43:103-110.

-Weiss EL, Lev-Dor R, Sharon N, Ofek I: Inhibitory effect of a high-molecular-weight constituent of cranberry on adhesion of oral bacteria. Crit Rev Food Sci Nutr 2002;42: 285-292.

Wilson T, Singh AP, Vorsa N, Goettl CD, Kittleson KM, Roe CM, Kastello GM, Ragsdale FR: Human glycemic response and phenolic content of unsweetened cranberry juice. J Med Food 2008;11:46-54.

Xiao J, Koo H: Structural organization and dynamics of exopolysaccharide matrix and microcolonies formation by Streptococcus $m u$ tans in biofilms. J Appl Microbiol 2009, E-pub ahead of print.
Yamanaka A, Kimizuka R, Kato T, Okuda K: Inhibitory effects of cranberry juice on attachment of oral streptococci and biofilm formation. Oral Microbiol Immunol 2004;19: 150-154.

Yamashita Y, Bowen WH, Burne RA, Kuramitsu HK: Role of the Streptococcus mutans gtf genes in caries induction in the specificpathogen-free rat model. Infect Immun 1993;61:3811-3817.

Yanagida A, Kanda T, Tanabe M, Matsudaira F, Oliveira Cordeiro JG: Inhibitory effects of apple polyphenols and related compounds on cariogenic factors of mutans streptococci. J Agric Food Chem 2000;48:5666-5671.

Zero DT: Dentifrices, mouthwashes, and remineralization/caries arrestment strategies. BMC Oral Health 2006;15:S9. 